\title{
O QUE FAZER NO ANO QUE VEM? ARTICULAÇÕES ENTRE JUVENTUDE, TEMPO E ESCOLA ${ }^{1}$
}

Sandra dos Santos Andrade* Universidade Federal do Rio Grande do Sul (UFRGS), Porto Alegre - RS, Brasil

RESUMO: Este artigo analisa o que dizem os jovens sobre futuro. $\mathrm{O}$ objetivo central é refletir sobre as possibilidades de articulação entre tempo, juventude e escolarização, com material empírico produzido em uma escola pública de Porto Alegre-RS. A metodologia de pesquisa foi a entrevista narrativa, analisada na perspectiva dos estudos culturais. Os jovens entrevistados frequentavam a oitava série, sendo a última oferecida pela escola, e se deparavam com a necessidade de pensar o que fazer no "ano que vem". Como resultados, a escola continua se mostrando como um importante lugar para a construção de um futuro de sucesso. A escolarização como imperativo se fixa, então, na certificação, no status e nos acessos que, supostamente, viabiliza.

Palavras-chave: Juventude. Tempo. Escolarização. Estudos culturais.

\section{WHAT TO DO NEXT YEAR? ARTICULATIONS BETWEEN YOUTH, TIME AND SCHOOL}

ABSTRACT: The article analyzes what youngsters say about future. The main objective is to reflect on the possibilities of articulating time, youth and schooling, with empirical material produced in a public school from Porto Alegre/RS. The research methodology was the narrative interview, analyzed from the cultural studies approach. The interviewed youngsters attended the eighth grade, being the last offered by the school, and faced the need to think of what to do "next year". As results, the school keeps showing itself as an important place to build a successful future. Schooling as an imperative is determined, then, in the certification, in status, and in the accesses that supposedly enables.

Keywords: Youth. Time. Schooling. Cultural studies.

"Pedagoga, mestre e doutora em Educação pela UFRGS. Professora Adjunta na Faculdade de Educação da Universidade Federal do Rio Grande do Sul (UFRGS). Membro do GEERGE - Grupo de Estudos em Educação e Relações de Gênero e do GEALFA - Grupo de Estudos e Pesquisas em Linguagem e Alfabetização. E-mail: <sandrasantosandrade@gmail.com>. 


\section{FUTURO}

Em uma pesquisa, perguntei a 12 jovens estudantes o que imaginam ou esperam do futuro. Mas, ao iniciar a escrita deste texto, percebi-me indagando: o que é mesmo futuro? Ao ler as narrativas dos(as) jovens, dei-me conta de que a pergunta é difícil, e a resposta, improvável. O futuro é quando? O amanhã, o logo ali, ou o futuro é daqui a alguns anos? E de curto ou de longo prazo? É possível pensar no futuro antes de se viver e projetar atentamente o presente? O futuro seria o resultado do modo como experienciamos e vivemos o presente? Se sim, faz sentido indagar sobre o futuro? Enfim, há como medir o tempo em períodos estanques, isolados, como passado, presente e futuro? Onde termina um e começa o outro?

Diante dessas indagações, apresento, neste texto, algumas reflexões acerca do que dizem os jovens sobre futuro e como interpretam a noção de tempo. Tomo como referência uma pesquisa realizada em 2013 com estudantes de uma escola pública do último ano do Ensino Fundamental. O material empírico da pesquisa foi produzido em uma escola da rede estadual de ensino da cidade de Porto Alegre-RS, localizada na zona urbana, e teve como metodologia de pesquisa, centralmente, a entrevista narrativa. Entrevistei jovens entre 14 e 16 anos que frequentavam a oitava série, sendo a última etapa oferecida pela escola, e se deparavam com a necessidade de pensar o que fazer no "ano que vem" - constituindo essa necessidade já uma experiência de futuro em curto prazo. A turma era composta por 20 alunos(as), mas somente 12 aceitaram participar das entrevistas individuais, embora todos(as) tenham participado dos outros momentos da pesquisa. Permaneci na escola e com os(as) jovens durante um semestre letivo, em torno de duas tardes por semana. Esse intenso estar com o outro (sujeito da pesquisa) me permitiu desenvolver certos modos de ver e, consequentemente, outros e novos modos de narrar esses(as) jovens em particular, porque cada lugar admite dizer coisas muito específicas e singulares daquele universo. E "são esses movimentos de ver e narrar que utilizamos para pôr em dúvida uma série de estratégias que visam a capturar indivíduos e multiplicidades humanas" (KLEIN; DAMICO, 2014, p. 68), neste caso capturar indivíduos jovens.

Ao longo do segundo semestre de 2013, construímos (eu e o grupo pesquisado) um vasto conjunto de procedimentos de investigação: observações, conversas informais, produções textuais, diários e entrevistas narrativas. Não foram todos previamente planejados, mas foram se colocando à medida que o campo se 
organizava, e algumas sugestões, como o diário ${ }^{2}$, vieram dos próprios jovens. Os materiais produzidos configuram-se como textos que possibilitam diferentes modos de narrar a si mesmo e, como pesquisadora, de ler e narrar o outro, sem a pretensão acadêmica de me colocar fora da narrativa, pois sou produto e produtora dela. Destaco, a partir disso, um impasse metodológico: a dificuldade da pesquisadora em colocar-se fora do discurso, do mesmo discurso que buscava mobilizar e fazer falar através dos(as) jovens. Não que esse impasse seja propriamente um "problema" para a pesquisa, mas materializa a impossibilidade de uma total isenção ou parcialidade na hora de fazer narrar. Isso porque, como sujeito da cultura, também sou acionada pelos discursos do senso comum; tanto dos discursos que me constituem, quanto do lugar de quem produz narrativas como pesquisadora. Várias vezes, ao reler as entrevistas, descobrime interrogando, sugerindo ou dando conselho aos(às) jovens e acabava interferindo e intervindo nas entrevistas de um modo pouco produtivo para fazer falar o(a) entrevistado(a). Dei-me conta, ainda, de que, com isso, perdia a oportunidade de fazer outras e novas perguntas que permitissem aos(às) jovens dizerem mais de si, e não das minhas preocupações de professora, intelectual, mãe e jovem que se constituiu em torno desse discurso de um futuro idealizado, de uma dada organização em torno de um projeto de vida.

Assim, na perspectiva dos estudos culturais em seu viés pós-estruturalista, faço uma análise das narrativas dos(as) jovens pesquisados(as), assumindo que a produção do sujeito (pesquisadora e pesquisados) sobrevém no domínio da linguagem,

[...] na relação com as forças discursivas que o nomeiam e governam sendo a escola um desses locais da cultura no qual se produz e nomeia o sujeito [...] por meio da forma como se organiza o espaço escolar, da seleção daquilo que conta como conteúdo válido ou não para ser ensinado, das relações que se estabelecem entre professores/as e alunos/as etc. (ANDRADE, 2014, p. 174)

Para compor as análises, são utilizados elementos das entrevistas narrativas. "Através da narrativa, é possível reconstruir as significações que os sujeitos atribuem ao seu processo de escolarização, pois falam de si, reinventando o passado, ressignificando o presente e o vivido para narrar a si mesmos", projetando o futuro (ANDRADE, 2008, p.49). Com isso, sinalizo a importância de pensar os tempos juvenis e a sua relação com a escola, indicando que o objetivo central deste texto é refletir sobre as possibilidades de articulação entre tempo, juventude e escolarização.

Nessa direção, pergunto-me, ainda, como a escola vem 
lidando com os novos modos de ser aluno(a) e jovem nestes tempos; principalmente se concordarmos com a ideia de que o tempo se transforma, (de)compõe, altera-se, em especial, na relação que grupos ou indivíduos estabelecem com as experiências vividas. Através da pesquisa que ora apresento, desenvolvo a hipótese de que a escola contemporânea ainda é considerada pelos(as) jovens, principalmente de classe média e média baixa, importante via para se alcançarem as projeções de futuro, não só pelo que ela ensina, mas também pelo que certifica e os acessos que possibilita no presente. Ao mesmo tempo, argumento que há um descompasso entre os tempos dos(as) alunos(as) e a escola atual, contudo nada se iguala ao status de ser escolarizado.

Problematizar essas questões só faz sentido numa era em que se intensificam cada vez mais os processos de globalização, quando o acesso à informação se dá em tempo real, a aceleração do tempo borra suas fronteiras e acabamos nos confrontando com a incoerência da ideia de controle: controle do tempo, controle da vida, controle do futuro... Nesse cenário, parece desbotar-se a antiga e cara noção de futuro produzida no início da modernidade: futuro como projeto individual e coletivo; futuro como algo a ser construído em longo prazo. Carmen Leccardi (2005) aponta que, na sociedade industrial, os jovens tinham projetos de ordem coletiva e de ordem individual, e que eles eram interdependentes entre si. Da realização dos projetos coletivos como democracia, cidadania, liberdade, igualdade etc. dependiam a realização dos projetos individuais como escolarização, trabalho, acesso a bens e serviços. Nos dias atuais, essa ideia de coletivo tende a apagar-se. Com isso, também se modifica a ideia de projeto produzida até então. "Hoje nos confrontamos, portanto, com construções biográficas de um caráter inédito, desvinculadas das formas de projeto tradicionalmente entendidas" (LECCARDI, 2005, p. 46).

Nesse panorama, esboroa-se, também, aquilo que tínhamos aparentemente tão claro e bem-definido, como a noção de tempo. Por isso, importa iniciar dizendo o que é apreendido por tempo neste texto. Tempo pode ser considerado, hoje, uma categoria construída, um produto da cultura. Como diz Alberto Melucci (1997, p. 10), "até o nascimento ou a morte, eventos por excelência do tempo natural estão perdendo sua natureza de necessidade biológica, tornando-se produtos de intervenção médica e social". Poderíamos acrescentar que os eventos do tempo, de um modo geral, são também de intervenção econômica, midiática, política, dentre outras. As estações, a lua e até mesmo o relógio não dão mais conta do que vivemos atualmente como tempo - ele é, além disso, resultado de como construímos e vivenciamos nossas experiências. 
Como nos explica Norbert Elias (1998), o que se entende por "presente, passado e futuro" depende dos grupos viventes em determinados períodos e como esses grupos se conectam continuamente com o passar das eras, já que essas conexões não cessam de se modificar. Segundo o autor, os entendimentos acerca de presente, passado e futuro "expressam a relação que se estabelece entre uma série de mudanças e a experiência que uma pessoa (ou grupo) tem dela. Um determinado instante, no interior de um fluxo contínuo, só adquire um aspecto de presente em relação a um ser humano que o esteja vivendo, enquanto outros assumem um aspecto de passado ou de futuro" (ELIAS, 1998, p. 63).

Nessa direção, tudo o que sabemos sobre a categoria tempo é aprendido na cultura, isso porque tudo o que sabemos sobre a categoria tempo é historicamente produzido. O tempo não é algo único, linear, constante; o tempo é flexível, instável, maleável, mutável, o que faz com que cada cultura experimente diferentes percepções, experiências de tempo. Mesmo dentro de uma mesma cultura, categorias como juventude, escolarização, classe social, gênero e cor da pele, por exemplo, podem contribuir para definir diferentes modos de habitar o/no tempo. Essas categorias podem adiantar ou adiar experiências que muitos campos do saber tomam como universais. Para a psicologia, por exemplo, a juventude é um tempo marcado por situações ancoradas, principalmente, no dado etário, medindo a vida humana, como afirma Elias (1998, p. 57), "com extrema exatidão", "[...] reconhecendo que os processos biológicos e sociais com que se relaciona esta escala de tempo têm um sentido único e irreversível”. Medir a vida somente através da idade desconsidera que questões sociais e culturais modificam as trajetórias individuais.

$\mathrm{Na}$ seção que segue, descrevo e analiso algumas respostas dadas à pergunta que norteou o diálogo que se estabeleceu com os(as) jovens ao longo das entrevistas narrativas: o que tu pretendes fazer no ano que vem? A resposta dada a essa questão me permitiu avançar no diálogo, investindo e explorando de modo individual nas narrativas, contribuindo para refletir sobre como compreendem/ vivem o tempo e a noção de futuro.

\section{O QUE FAZER NO ANO QUE VEM?}

Sandra: E trabalbar, tu já penson ou tu vai só estudar ano que vem?

Tamires: É, eu e a minha mãe, a gente já pensou, mas ela disse que primeiro eu tenho que estudar para eu conseguir trabalhar, ter um bom trabalho, primeiro o estudo e depois, talvez, se en quiser muito, ela deixe, mas primeiro lugar é sempre o estudo. 
Sandra: E tu tá pensando em só estudar no ano que vem ou quer trabalhar também?

Fernanda: Eu queria, mas, tipo assim, estágio, alguma coisa, mas é muito pesado, eu queria só estudar e nem os meus pais querem que eu trabalhe muito cedo. ${ }^{3}$

Acredito na impossibilidade de, nos tempos atuais, capturar o futuro, ou, como escreve Leccardi (2005), "colonizar o futuro", como já se confiou que fosse possível em outros tempos; mas acredito, também, que o investimento no amanhã (seja ele para daqui a pouco ou para daqui a muito tempo) ainda orienta e estabelece os fazeres do presente de uma parcela significativa da população juvenil e de seus familiares, como vemos nos excertos acima. E, boa parte das vezes, essa ideia e essa organização de futuro estão, necessariamente, atreladas ao processo de escolarização. As duas jovens falam em estudar primeiro e trabalhar depois, como um desejo compartilhado com a família. O estudo mostra-se como a possibilidade de conquistar "um bom trabalho", por isso, aproveitar essa oportunidade que se coloca no presente é inquestionável. Assim, inspirada em Leccardi, chamarei esse amanhã de "presente estendido", extensão do tempo presente para dar continuidade à experiência vivida. Pois, segundo a autora, "nos quadros temporais de fins do século XX, em suma, o presente (ora mais, ora menos estendido) aparece como a única dimensão temporal disponível para a definição das escolhas, um verdadeiro horizonte existencial que, em certo sentido, inclui e substitui presente e passado" (LECCARDI, 2005, p. 46).

As narrativas juvenis mostraram-se heterogêneas, quando perguntados(as) sobre o que fariam no ano que vem; mas decidir o que fazer no próximo ano, para esses(as) jovens, implicava uma "definição das escolhas", uma tomada de decisão dentro dessa ideia de presente estendido. Decidir o que fazer e/ou para onde ir se mostrou uma escolha difícil para a maioria: uns não sabiam o que fazer, outros receavam a definição da escola pública (esta é feita pelo Estado), outros faziam o que a família decidia como sendo o melhor, mesmo não concordando com isso, e havia os que ainda não tinham pensado nisso. Mas todos(as) os(as) jovens mencionaram a escola como uma necessidade, mais do que isso, como um imperativo.

Há uma infinidade de práticas discursivas atualmente disseminadas em diferentes espaços culturais a falar sobre (a inventar) a escola e seus processos de escolarização como imprescindíveis. $\mathrm{Na}$ academia, por exemplo, "algumas publicações pedagógicas e as pautas da grande mídia, no Brasil e em outros países, têm profetizado, nos últimos tempos, o desaparecimento ou a substituição da escola e dos conhecimentos que (re)produz" (COSTA, 2003, p. 15). Em contrapartida, essa mesma 
grande mídia e a academia "têm-lhe dado destaque ímpar e crescente em suas tramas e narrativas" (COSTA, 2003, p. 15).

A escola é tematizada no nosso meio social como uma importante instituição para a transformação dos indivíduos e das sociedades que estes integram e, na mesma direção, tais ditos foram reiterados pelos(as) jovens da pesquisa, visibilizando que alguns discursos já fazem parte do senso comum. O que é dito no senso comum não constitui uma totalidade discursiva. O senso comum é composto por fragmentos de discursos que, pronunciados repetidas vezes ao longo do tempo, "ou destacados de discursos em uma dada conjuntura política e social", acabam sendo assumidos como verdades (PINTO, 1989, p. 43). O discurso do senso comum é fragmentado, contraditório, fluido, está em toda parte e ao mesmo tempo não pertence a nenhum discurso original. Esse processo de fluidez pode tanto fragilizá-lo, como, ao contrário, dar-lhe força. Tem, portanto, "uma enorme capacidade de dar sentido à vida cotidiana e uma enorme potencialidade de ser articulado a diferentes visões de mundo" (PINTO, 1989, p. 45).

Grande parte dos enunciados trazidos pelas(os) jovens entrevistadas(os) destaca a importância da escola como garantia para um futuro melhor e, por isso mesmo, reforça ou refuta boa parte dos discursos produzidos em torno dela e dos processos de escolarização. Cabe esclarecer que enunciado não precisa ser necessariamente uma frase, mas é parte de uma formulação oral ou escrita que nos permite decidir, através da análise, se faz sentido ou não, se é aceitável ou interpretável. O enunciado exige uma materialidade; ele precisa ser dito, registrado, deixar uma marca (na memória ou em algum espaço). O enunciado possui uma existência específica, e essa existência aparece

[...] como relação com um domínio de objetos; não como resultado de uma ação ou de uma operação individual, mas como um jogo de posições possíveis para um sujeito; não como uma totalidade orgânica, autônoma, fechada em si e suscetível de - sozinha - formar sentido, mas como elemento em um campo de coexistência; não como um acontecimento passageiro ou um objeto inerte, mas como uma materialidade repetível. (FOUCAULT, 2000, p. 125)

Os enunciados repetidos e materializados nas falas dos(as) jovens os(as) constituem enquanto sujeito aluno(a) e visibilizam o conjunto discursivo que os(as) interpela ou nos quais se sentem endereçados. Ao mesmo tempo, os(as) jovens trazem rastros de discursos que saúdam a escolarização como garantia de futuro, como via de acesso a melhores trabalhos, a conquista de cidadania, de autonomia, de participação social. Vê-se, também, a escolarização atrelada à noção 
de projeto de vida. Ou seja, as coisas ditas sobre a escola passam a fazer parte daquele conjunto de pressupostos sociais e culturais que acabam sendo reproduzidos em nossa cultura, passam a ser aceitos como dados imutáveis e imprescindíveis na constituição de um sujeito.

O período da juventude coloca aos(às) jovens a necessidade de começar a enfrentar o tempo, o tempo presente e o tempo porvir, o que não acontece de modo tão incisivo na infância. Isso se dá tanto por uma pressão social e cultural, como por um pressuposto biológico que coloca a juventude como lugar de passagem, de transição da infância para a vida adulta, e a juventude como tempo de preparação para o futuro, sendo a escola, mesmo na atualidade, um dos principais lugares para essa preparação. Vivian Weller (2014, p. 137) argumenta que o termo transição está ligado "à saída de um lugar para outro" e que a passagem de uma "determinada posição ou condição no presente implica projetar-se para um futuro". Mas, para fazer isso, o(a) jovem precisa estar em condições de realizar essa projeção, o que implica um processo de aprendizagens e de tomada de decisões que passa, também (ou principalmente), pela escola; pois "projetar-se constitui um elemento importante para a organização da identidade [diria das identidades, já que os/as jovens são múltiplos em si mesmos/as] individual e coletiva dos jovens" (WELLER, 2014, p. 137). Por mais que os ritos de passagem tradicionais estejam perdendo sua importância cultural e social, ainda é na juventude que a organização e a cobrança de um preparo para o futuro prevalece. E a escola desponta, na indicação de vários(as) entrevistados(as), como o local legítimo de aprendizagem e de preparação, como mostram as palavras de Cadrícia:

Cadrícia: É, o resto tá indo, o resto tá bom assim [estudos]. É só matemática que tá... Eu quero estudar muito, en quero conseguir uma bolsa e eu acho que eu vou conseguir no Anchieta [uma das mais renomadas escolas privadas de Porto Alegre].

Sandra: Tu tá tentando a bolsa no Anchieta?

Cadrícia: Isso, en já fiz a prova. Eu quero, en vou fazer cursos, que tem cursos, en queria fazer lingua japonesa, que hoje em dia é uma das linguas mais faladas além do inglês. Mandarim, também, e são bem difíceis. Mas eu acho importante também informática, essas coisas... e fazer uma coisa para poder fazer intercâmbio.

Sandra: Para onde tu quer [ir]?

Cadrícia: Todo o lugar, eu não me importo com lugar assim, eu acho legal Europa e coisa e tal, mas en gosto de conhecer a cultura de interior sabe, eu gosto disso.

Sandra: E porque tu escolheu o Anchieta?

Cadrícia: Não, porque eu não escolbi o Anchieta, en tô fažendo prova para várias escolas [privadas]. 
A fala de Cadrícia é emblemática da jovem antenada com seu tempo, mas também atrelada às tradicionais cobranças de investimento no futuro, socialmente construídas e bem de acordo com o seu tempo vivido. São questões que desvendam certa ambiguidade, pois Cadrícia está conectada com seu tempo, mas de olho naquele futuro que tem sido tomado como o mais adequado aos(às) jovens de hoje; então é preciso não perder tempo e fazer todo o possível: conquistar uma bolsa de estudos, aprender japonês, mandarim e informática e fazer um intercâmbio, além de fazer o Ensino Médio em uma escola privada, porque, segundo ela, o ensino é mais forte. "A juventude, nesta direção, é concebida como momento de realizar, descobrir, experimentar, e essas vivências são marcadas pela noção de tempo. É agora, neste momento, que os jovens são convocados/as a organizar a vida e preparar-se para o futuro" (MEYER; FÉLIX, 2014, p. 185). Por esse mesmo viés, Melucci (1997, p. 10) aponta que, para os jovens contemporâneos, "a experiência de tempo como possibilidade, mas também como limitação, é uma maneira de salvaguardar a continuidade e a duração; uma maneira de evitar que o tempo seja destruído em uma sequência fragmentada de pontos, uma soma de momentos sem tempo".

Desse modo, o conceito de juventude é compreendido, no contexto deste texto, como uma condição histórico-cultural, compondo múltiplas representações; contudo, entendo que essas representações não são dadas, nem fixas. Há representações, por exemplo, que associam a juventude a períodos de desordens e crises; juventude como agente causador de problemas ou, ao contrário, juventude como composta porindivíduos dotados de energia, vibração, agilidade, rapidez, capazes de demonstrar sua inconformidade com a ordem social vigente. E, como toda categoria socialmente construída, deve ser analisada em suas diferentes dimensões - materiais, políticas, históricas, culturais, temporais -, já que estas acarretam diferentes modos de compreender a juventude e de ser jovem. Para alguns segmentos, o sujeito jovem é pensado como um indivíduo que, biológica, mental e socialmente progride da fase infantil para a fase adulta, consistindo a juventude em uma fase intermediária. Ou seja, são representações compostas por discursos de diferentes ordens e de diferentes campos do saber, que tanto convergem como divergem sobre o que seja juventude e como se vive esse tempo.

A confluência dos múltiplos discursos que agem sobre os sujeitos e seus efeitos nos faz perceber o quanto as coisas ditas no âmbito da - ou em torno da - cultura são produzidas e/ou inventadas, fabricando jovens de determinados tipos e com determinadas 
perspectivas, que, com isso, experienciam o mundo em diferentes tempos. Rosa Fischer (2001) entende que os discursos dizem respeito a um conjunto de enunciados de um determinado campo do saber e que esses enunciados sempre existem como prática, "porque os discursos não só nos constituem, nos subjetivam, nos dizem 'o que dizer', como são alterados, em função de práticas sociais muito concretas. Tudo isso envolve, primordialmente, relações de poder" (FISCHER, 2001, p. 85). Os discursos instauram verdades, produzem sentidos e formam os sujeitos. Eles "constroem e implementam significados nas sociedades por meio de diferenciações que dividem, separam, incluem e excluem e que, por se constituírem em dinâmicas de poder, produzem e legitimam o que, aí, é aceito como verdade" (MEYER, 2000, p. 55).

É, pois, no interior dos processos de escolarização que diferentes práticas discursivas são postas a falar sobre e para a juventude, incluindo e excluindo, mostrando a cada um(a) os lugares que podem e devem ocupar. Nesses discursos, sutilmente hierarquizados e entrecruzados, ou seja, nesse mosaico discursivo, jovens vão construindo suas identidades, constituindo-se enquanto sujeitos e constituindo, simultaneamente, representações de futuro (ANDRADE, 2008).

A partir disso, trata-se de problematizar o discurso que reitera que juventude seja apenas um tempo de preparação ou transição para a vida adulta ou uma etapa a ser vencida com um fim preestabelecido, que é o de atingir a vida adulta e as suas consequentes responsabilidades. Fala-se disso como se essa passagem fosse vivida de modo igual por todos(as), de forma linear e estável; no entanto,os tempos que nós experimentamos são muito diferentes uns dos outros e, às vezes, até opostos. "Há tempos muito difíceis de medir - tempos diluídos e tempos extremamente concentrados" (MELUCCI, 1997, p. 7), e as narrativas evidenciam as disparidades nos modos de pensar e viver esse tempo, as diferentes perspectivas e imprecisões nos modos de lidar tanto com o que concebemos como presente, quanto como futuro.

Sandra: Hã, mas tu nem te inscreveu nas escolas públicas ainda?

Dudu: Não, porque ficou muito em cima quando eu fiquei sabendo.

Sandra: Hoje é o último dia.

Dudu: É, acho que é hoje, que é dia 10 agora a prova.

Sandra: Pois é, ai tu vai ficar um ano...

Dudu: É, vou ficar um ano ai esperando.

Sandra: Ai tu pode continuar no Sneipers ${ }^{4}$ e fazer todos os dias de tarde? 
Dudu: Sim, daí eu acho que vou estudar de manhã [escola] que daí fica bom para estudar de tarde. Eu posso estudar lá pelo Sneipers daí.

Sandra: Bom, pelo menos tu vai ter uma ocupação. Então, tu já sabes que teu desejo de futuro é isso [seguir carreira militar]?

Dudu: É, a princípio sim.

Eduardo faz uma fala confusa na tentativa de explicar o que faria no ano seguinte. Na sequência, diz não saber exatamente o que fazer, isso porque seu presente era incerto, poderia ter que repetir o ano letivo, como de fato aconteceu ${ }^{5}$. Assim, como falar de futuro se o presente ainda é instável? Nesse exemplo, ainda não é possível fazer uma escolha ou tomar uma decisão. Desse modo, o presente se estende, de forma quase indefinida, incerta, imprecisa, e se mescla ao futuro que parece logo ali. Pode-se dizer que o presente se apresenta como um gerúndio eterno ou uma horizontalização do tempo no presente, e não no futuro. $\mathrm{Ou}$, ainda, que "o presente pode ser visto enquanto instante vazio, mera impossibilidade de ser vivida. Aquilo que está sempre a ser capturado no fluxo do tempo pelo passado e futuro, sem nunca ser por si" (COSTA; FONSECA, 2007, p. 6).

$\mathrm{Na}$ citação acima, coloquei em relevo a frase "Bom, pelo menos tu vai ter uma ocupação", dita por mim durante a entrevista com Dudu, para reafirmar a dificuldade da pesquisadora de, em algumas situações, não conseguir manter o devido afastamento dos ditos pelos sujeitos da pesquisa; senti-me tocada pelas histórias de vida de meus entrevistados(as) e impliquei-me com elas.Mas, ao mesmo tempo, o excerto materializa e humaniza a pesquisa como algo produzido, e produzido por pessoas de carne e osso, que se envolvem e se implicam, evidenciando que não há neutralidade no processo de pesquisar.

Como já referido, a juventude não é uma essência em si mesma; é uma construção e uma condição que se dá em diversos tempos e lugares, de diferentes formas. Nem todas as pessoas de uma mesma idade vão viver esse período do mesmo modo, nem se tornarão adultos no mesmo espaço de tempo; tudo isso é dependente de contextos e circunstâncias sociais, geográficas e culturais específicas. Assumindo essa perspectiva, remeto-me a juventudes no plural, pois, como já enfatizado, ela adquire significados distintos de acordo com dimensões como classe, gênero, raça, religião, região, dentre outras (ANDRADE, 2008; DAMICO, 2011; FÉLIX, 2012). Para Melucci (1997 p. 9), a perspectiva temporal do adolescente - e eu diria das juventudes - "tornou-se um tema interessante de pesquisa, porque a biografia dos dias de hoje tornou-se menos previsível, e os projetos de vida passaram mais do que nunca a depender [também] da escolha 
autônoma do indivíduo". Isso é relativo, pois as escolhas que se fazem e os anseios e desejos que se têm para o futuro podem mudar, tanto pelas condições de possibilidade para realizá-los quanto por outras e novas escolhas que se podem fazer.

$\mathrm{Na}$ seção seguinte, reflito sobre como a localização geográfica da escola implica, em alguma medida, nos modos como os jovens vislumbram o futuro e como investem nele, entendendo que a localização também pode refletir um pertencimento de classe social.

\section{TEMPO, ESCOLA E JUVENTUDE}

Não imaginava, a princípio, que a localização geográfica e a situação econômica da escola investigada implicariam, de modo tão intenso, em distintos modos de ser jovem e pensar o futuro. É senso comum imaginar (como eu imaginava) que estudantes de escolas públicas tenham um mesmo perfil cultural, social, econômico, independentemente do local onde a escola esteja localizada, o que foi logo desconstruído ao estar lá.

O bairro onde se encontra a escola foi criado por ato de lei em dezembro de 1959 e é considerado uma zona nobre da cidade de Porto Alegre, principalmente na sua parte alta, local onde fica a escola. Assim, é uma escola pública ancorada em um bairro de classe média alta, que abriga filhos e filhas de trabalhadores do bairro e moradores do seu entorno, que, apesar de possuírem escolas mais próximas das suas casas, preferiam se deslocar até a escola da pesquisa, justamente por sua fama de boa escola. "Parece uma escola particular", afirmaram alguns alunos(as). Essa afirmação era traduzida, nas vozes dos(as) jovens e da direção da escola, pela organização do espaço: limpo, bem-conservado e sem pichações; pela tranquilidade e pela educaşão de seus frequentadores; não há registro de violências ou agressões, não há registro de uso de drogas. Percebe-se certo bom-mocismo no suposto comportamento dos(as) jovens. Uma das entrevistadas, por exemplo, aponta que há muita diferença entre criar uma criança na vila e no bairro. Ela é filha de um zelador, que, por trabalhar em um dos prédios do bairro, também mora nele há alguns anos; a mãe trabalha em uma agência de câmbio trocando dinheiro, e ela convive com algumas jovens moradoras do prédio.

Ju: Ai eu senti diferença, eu senti muita diferença em mim depois que eu vim de lá [da vila]; lá eu era bem mais maloqueira, brincava na rua e tal. Hoje não, hoje eu não gosto disso, gosto de ficar em casa, gosto de ficar lendo, coisa do tipo [...] agora que eu fico lá [na casa que a familia possui na vila] no final de semana eu vejo, porque as minhas amigas da creche 
ainda moram lá, a gente morava na mesma rua, era tudo muito perto; dai eu vejo que elas já usam umas roupas diferentes, já tão lá com namorado de três, quatro anos, aí eu já acho aquilo fora da minha realidade.

Parece que, para Ju, estar atualmente morando nesse bairro e frequentando uma escola que nele se situa foi suficiente para que se sentisse posicionada de modo distinto de sua comunidade de origem. Os discursos da classe média se mostraram compondo os modos de dizer e ser de Ju, de tal forma que é capaz de identificar e nomear as diferenças que entende existir entre ela e suas antigas amigas, definindo que o território é um significativo marcador de fronteiras e pertencimentos; que um lugar também pode produzir identidades e definir projetos de futuro. Em outro excerto, Shape Door reforça o argumento de Ju quando perguntado sobre por que foi estudar na escola da pesquisa:

Sandra: [...] é que eu queria entender porque que tu veio estudar aqui, nessa escola, porque deve ter escolas mais perto [da tua casa].

Shape Door: Tem, deve. Tinha uma escola perto do colégio que eu fiz. o pré, mas ai a minha mãe achou melhor me trazer para cá, porque aquele colégio era cheio de maloqueiro e não sei o que... e dai a minha mãe achou melhor me trażer para cá.

Sandra: E tu acha que aqui o colégio é melhor?

Shape Door: É, bem melhor.

Sandra: Em que sentido?

Shape Door: Em sentido de pessoas, amigos, convivência, professores, é... segurança também, um pouco mais.

Na mesma direção aqui apontada, Dayrell e Carrano (2014) destacam a relevância analítica de refletirmos sobre a questão do espaço e do lugar na sua relação com a escola. Isso nos permite pensar, segundo os autores,

[...] a maneira como os jovens constroem e dão significados aos espaços, sejam por meio dos locais que frequentam, dos estilos de vida, da produção de culturas juvenis, dos padrões de consumo, das relações de poder, dos espaços de lazer ou por meio da sociabilidade. Permite-nos também pensar de que formas os espaços vividos, construídos e ressignificados pelos jovens influenciam suas escolhas e seus projetos de vida. (DAYRELL; CARRANO, 2014, p. 119)

Fui percebendo, então, que os modos de projetar o futuro dos(as) jovens estudantes podem estar relacionados ao lugar em que a escola se localiza, o lugar onde esses jovens moram, com quem se relacionam, e o lugar profissional que os familiares ocupam, ou seja, com seus pertencimentos. O que pareceu possibilitar, também, 
um modo mais em médio prazo de projeção e realização de futuro, quando comentavam, por exemplo, sobre o desejo de fazer uma faculdade, abrir um negócio próprio, viajar pelo mundo. Isso talvez se dê porque possuem suas necessidades básicas essenciais atendidas (alimentação, vestimenta, escola, moradia) e, segundo eles e elas, de modo satisfatório. Ou seja, esses são condicionantes econômicos que permitem aos(às) jovens da nova classe média outras formas de projetar o futuro, pois o seu presente lhes parece menos incerto e estendido - mesmo que efetivamente não seja - e se percebem com mais garantias de realização e de inserção futura.

Ao mesmo tempo, o desejo de participação e ocupação desses outros espaços vai-se produzindo e fortalecendo em função do recrudescimento dos discursos que reiteram esses modos de viver a juventude como tempo de preparação para algo. Compreendem e ressaltam, entretanto, a necessidade de realizar um esforço individual para alcançar a consumação de seus sonhos. Falam desse tempo acelerado e da necessidade de estar sempre atualizados, aproveitando as oportunidades que surgem no presente.

Percebo que a dimensão de classe é um importante marcador social eidentitário, que interfere de modo significativo nas possibilidades de os(as) jovens projetarem o futuro. A classe social, na sua intersecção com outros marcadores, produz diferenciações e pertencimentos, contribuindo para a exclusão ou a inclusão dos indivíduos de determinados privilégios ou direitos. Não é comum pensarmos em classe como uma identidade construída culturalmente em meio a tantas outras a que somos sujeitos; classe, contudo, é uma questão histórica composta por uma infinidade de experiências que se dão umas em relação com as outras, num processo que é contínuo, permanente, e não uma categoria estrutural. Ou seja, a classe social implica múltiplas dimensões culturais que estão inter-relacionadas com ela.

Quanto a isso, Guimarães (2002, p. 10) escreve que

O conceito de classes sociais capitalistas nada mais é que um recurso analítico para referir-se a este tipo de exploração, que, na prática social e no mundo "real", aparece sempre misturado a hierarquias de gênero, de raça, etnia ou outra forma qualquer de outsiders. O problema teórico deve ser colocado como de exploração ou apropriação diferencial de recursos.

Entendo, com isso, que classe não se faz sozinha e que a pobreza ou a riqueza são um dado relacional; quem conta como sendo pobre ou rico depende do que e do quanto têm os outros. Além disso, a dimensão de classe está envolvida, de modo intenso, com nossas outras posições de sujeito e, ao mesmo tempo, implicada 
com a produção de tais posições. Nunca somos uma única coisa, não somos parte de uma única instância de identificação.

Em diferentes momentos, as falas dos(as) jovens pareciam repetir discursos hegemônicos sobre futuro que circulam na família, na mídia e, centralmente, na escola. É importante dar-se conta de que a necessidade de organização para o futuro pode não ser, efetivamente, uma necessidade dos(as) jovens entrevistados(as), mas estes conhecem o que pensa o mundo adulto e a própria escola sobre isso. As perspectivas de futuro apresentadas pelos(as) jovens pesquisados(as), por exemplo, não incluíam casamento e filhos cedo; muitos nem queriam filhos, destacavam a necessidade de independência financeira, da realização de uma graduação para chegar a uma profissão. A maioria dos(as) jovens ainda era virgem, ao menos em seus relatos, e não queriam namoro firme naquele momento. Não conseguiam precisar tempo para a realização de tais projetos, pois a ideia de planificar as experiências em anos parecia difícil.

Não sabiam dizer ou achavam que não faziam nada no presente para facilitar esses projetos de futuro, creio que em função de uma cobrança do mundo adulto de que a juventude é o tempo certo para investir no amanhã. Segundo Dayrell e Carrano (2014, p.106), "nega-se assim o presente vivido". Um presente estendido, que prevalece, prepondera; quando a globalização, a aceleração do tempo, o borramento das fronteiras entre presente e futuro suscitam a imprecisão e a heterogeneidade da experiência do vivido e a insegurança social. "Aliada ao espaço, a condição juvenil expressa uma forma própria de viver o tempo. O tempo presente predomina e interroga o futuro e o passado. O hoje é a dimensão temporal onde muitos jovens concentram sua atenção" (DAYRELL; CARRANO, 2014, p. 120). Há uma vontade de atingir objetivos mais amplos e gerais, mas de grande fôlego, como fazer uma faculdade, abrir um negócio ou viajar, mas há, também, a suspeita da imprecisão e da dificuldade de controlar esses objetivos.

É possível pensar que o que os(as) jovens falam sobre casamento, estudo e filhos se aproxima da noção idealizada na cultura do que seja futuro e de que tudo isso pode estar sendo dito como reprodução daquilo que já ouviram de modo reiterado, em casa, na escola, na mídia, como sendo desejável para o futuro: um futuro inventado. É até esperado que digam, para que não se sintam fora da normalidade. Mas acredito, também, que essas e esses jovens de fato desejam estender o presente para viver mais intensamente o tempo de juventude, na tentativa de garantir maiores possibilidades de futuro. 
Assim, projetar o futuro pode ser uma necessidade colocada pela cultura ocidental, a fim de produzir um sujeito (pre)determinado, e esses(as) estudantes se mostram, se não constituídos, ao menos implicados com tal discurso. Por isso, não importa muito se o(a) jovem gosta da escola ou do que ela ensina, mas importam os efeitos que os ditos escolares produzem em termos do amanhã. Ao mesmo tempo, a escola não consegue interessar todos(as) os(as) estudantes de modo igual, como indica um dos jovens quando escreve em um texto que a escola "é um castigo de Deus", mas que precisa dela para realizar seu sonho profissional.

Como estimular os jovens para que tenham projetos de vida fortemente alicerçados no conhecimento escolar, nesse contexto? Muitas vezes, os jovens revelaram uma fragilidade ao se expressarem sobre seus projetos de futuro. Parece que o fato de vivenciarem experiências tão precárias, em que a escola não dialoga com seus desejos e demandas quanto à inserção futura, não lhes permitia formular planos que ultrapassassem o tempo presente. (LEÃO, 2011, p. 108)

Concordo com o argumento de Geraldo Leão, mas talvez uma das dificuldades de a escola interpelar seus(suas) alunos(as) e refletir com eles(as) sobre encaminhamentos futuros seja a de lidar com as diferenças entre os próprios sujeitos jovens e capturar sua multiplicidade, de reconhecer que as noções de futuro que estes(as) possuem não são fixas, nem estáveis, nem iguais, e que tais noções entram em choque com noções de tempo da própria escola. Para um currículo escolar engajado com seu tempo, a fim de dar conta das necessidades do(a) aluno(a) contemporâneo(a), talvez fosse importante ponderar, então, que os entendimentos dos(as) jovens sobre tempo e tempo futuro são diferentes e conflitantes; a escola, grande parte das vezes, incorpora e representa uma noção específica, única e universal de futuro e de juventude.

Como pesquisadora, coloco em xeque a representação de futuro que me orienta, mas, no momento da entrevista, dei-me conta da dificuldade que é desvencilhar-me dos outros atravessamentos identitários que me constituem e abarcam - escolarizada, professora, mãe, mulher. Esses atravessamentos competem uns com os outros, interferindo no modo de perguntar a esses(as)jovens sobre o futuro. Uma postura que, se não vigiada, leva a ver os(as) jovens como sujeitos em falta, e não como sujeitos que apontam para o que falta na escola. Ou seja, enfatizam-se "os aspectos negativos e peças idealizadas que faltariam para compor o nosso tipo ideal de jovem" (DAYRELL; CARRANO, 2014, p. 108). Do mesmo modo, os(as) professores(as) e os(as) funcionários(as) que organizam as escolas, 
hoje, também são sujeitos de outro tempo e foram constituídos de outros modos. Romper com essa lógica cartesiana de futuro e de ver a juventude requer um exercício vigilante, constante, contínuo e paciente de nós mesmos e da sociedade em que nos inserimos; o que pode justificar, em alguma medida, a dificuldade para romper com os currículos escolares vigentes, pois isso pode significar, por vezes, nos apartarmos de nós mesmos e de certezas tão caras.

Ao tentar alternativas para os currículos que se tem e atentar para essa relação juventude e escola, "um primeiro passo é constatar que a relação da juventude com a escola não se explica em si mesma: o 'problema' não se reduz nem apenas aos jovens nem apenas à escola e seus professores" (DAYRELL; CARRANO, 2014, p. 103). É simplório culpar um ou outro - os(as) jovens ou a escola, ou,ainda,os(as) professores(as) - individualmente, pois vivemos numa rede em que as relações se desenvolvem e se estabelecem, e a comunidade escolar é "parte integrante da sociedade e expressa, de alguma forma, os problemas e desafios sociais mais amplos" (DAYRELL; CARRANO, 2014, p. 103).

Ao mesmo tempo, narrativas como a de Shape Door reforçam a escolarização como condição necessária para se ter um "bom” futuro:

Shape Door: [...] é que nas duas primeiras [bimestres letivos] eu era muito da zoação, de conversar, e dai a minha mãe me deu um toque que era bom eu estudar porque isso ia acarretar no meu futuro, lá na frente, dai eu me toquei e disse que tem que estudar.

Sandra: E tu concorda com isso?

Shape Door: Ah sim, porque é bom tu ter uma educação, tu ter um futuro bom.

Sandra: Tu acha que ter um futuro bom depende de ter estudado?

Shape Door: Sim e ter educação.

Shape Door traz a noção de escolarização como imperativo, indicando esta como uma condição necessária tanto para se atingirem objetivos de futuro, como formação profissional e trabalho, quanto para se tornar educado. Compreendi, aqui, a expressão "ter educação" como a aquisição daqueles conhecimentos que extrapolam os conteúdos escolares e incluem outras experiências de vida, sociais e culturais. Essa apresentação da escola como imperativo para se "ter um futuro" já foi observada em outra pesquisa que realizei com jovens de periferia ${ }^{6}$; nela, esse enunciado também se replicava de diferentes formas.Isso me permite dizer que, apesar de todas as críticas que sofre a escola, ela ainda permanece, para a maioria dos(as) jovens estudantes - seja da zona urbana ou da periferia, sejam homens ou 
mulheres, brancos ou negros -, como a principal via de acesso para o sucesso no futuro. Geraldo Leão (2011), em uma pesquisa realizada no ano de 2009 com 245 jovens de diferentes regiões do Pará sobre seus projetos de vida e a contribuição da escola nisso, também constatou a presença da escolarização como imperativo, mesmo que os(as) jovens apresentem motivações diferenciadas para estar e ficar nela. Ele aponta que muitas reformas educacionais foram

\footnotetext{
[...] impulsionadas por múltiplos fatores de ordem econômica, política e social, [e] ancoraram-se no discurso de que a educação constitui-se em um capital, absolutizando muitas vezes a sua capacidade para promover o desenvolvimento social. Elas vieram acompanhadas de um discurso redentor e salvacionista: "a escola como passaporte para o futuro". Criou-se um consenso social em torno da centralidade da educação como garantia de um "futuro melhor" com um forte apelo social. (LEÃO, 2011, p.104)
}

Em um texto sobre a mesma temática, Vivian Weller (2014, p. 139) indica que a escola possui a forte função de servir como passaporte para o futuro; que esta, "enquanto instância de socialização secundária, desempenha [ou deveria desempenhar], juntamente com a família, um importante papel na elaboração de projetos" de vida. A autora aponta, além disso, que uma das dificuldades para a escola incluir a temática de projetos de vida em seu currículo "é a pouca prioridade dada a esta função, julgando que a elaboração de projetos de vida é papel das famílias e que as instituições de ensino devem concentrar seus esforços na preparação do jovem para o mercado de trabalho" (WELLER, 2014, p. 139). Mas aí me pergunto: onde se distanciam a preparação para o mercado de trabalho e a projeção de futuro?

Talvez a inserção em grupos econômicos mais bemposicionados, de que participam os(as) jovens(as) pesquisados(as) e seus familiares, explique a importância atribuída à educação escolar e a não preocupação - ou a não necessidade, ou como projeto de futuro próximo - de trabalhar no ano seguinte. A escolarização ainda é compreendida como a grande chave para uma melhor perspectiva de futuro, vide a valorização da escola que frequentavam pela sua organização, por não ter brigas, situações de violência ou uso de drogas, pelo comportamento adequado apresentado e cobrado dos(as) alunos(as), como já citado anteriormente. Também viam a escola como possibilidade de acesso a outras experiências, como em algumas políticas públicas e/ou projetos. Dentre eles, foram citados, por exemplo, Projeto Pescar e Jovem Aprendiz:

Sandra: E tu só pensou em fazer o $2^{\circ}$ grau [no ano que vem]? Não pensou em fazer um curso técnico ou profissionalizante, não chegon a te passar essa ideia? 
Yan: Não, eu só quero fazer no ano que vem o Jovem Aprendiz:

Sandra: Ah, tu vai fazer?

Yan: Vou, vou fazer.

Sandra: Tu já te inscreveu?

Yan: Já, só tem que esperar o ano que vem, porque a minha mãe tem que fazer um monte de coisas $[\ldots]$

Sandra: Mas já tá inscrito?

Yan: Já, já.

No desejo de dar continuidade ao Ensino Médio em uma escola que se mantivesse dentro dessa perspectiva ou desse padrão, algumas meninas faziam seleção em colégios privados para obtenção de bolsas, outras estudavam para seleção no Colégio Militar, outras famílias cogitavam pagar uma escola privada caso não houvesse outro modo de ingressar em uma escola considerada por eles(as) como "boa". No período final do campo, também se dava o período final para a inscrição em escolas públicas, visando ao próximo ano. Havia uma escola como a mais aspirada, não apenas por estar localizada no mesmo bairro da escola atual, mas, principalmente, pela fama que a escola goza hoje, de ser uma das melhores escolas públicas de Ensino Médio da cidade. Todas as médias da escola no Exame Nacional do Ensino Médio (Enem) estiveram acima da média nacional. A escola apresenta uma taxa de abandono de apenas 1\% no Ensino Médio (em relação a 10,8\% da média nacional) e, em compensação, o índice de reprovação é de 22,3\% (em relação a 11,6\% da taxa nacional). $O$ alto índice de reprovação é tomado como fator de qualidade pelos(as) jovens da pesquisa, sinônimo de rigor, de ensino "forte".

Apesar da supervalorização da escola e das aprendizagens lá feitas, foi possível perceber a pouca relação entre as aprendizagens escolares e a projeção para o futuro; há diversas falas nesse sentido. E, mesmo quando repetem o discurso senso comum da importância da escola e de que ela é boa sempre, não conseguem argumentar sobre isso ou justificar a ideia, como mostra Fernanda.

Sandra: Tu acha que as coisas que tu aprendeu nas escolas que tu estudou, não só aqui, elas fizeram alguma diferença na tua vida?

Fernanda: Fizeram.

Sandra: Como?

Fernanda: Tipo, muitas coisas também que quando eu estudava, ah, são pequenas coisinhas assim que a gente leva. Ah, tipo quando eu estudei na escola X eu tinha as minhas amigas 
tudo lá, mas que nem eu estudei em Viamão lá era uma escola que se fosse hoje, se eu tivesse um filho eu não botava lá, porque era muito horrivel, dava briga, era coisas assim. E tipo que nem aqui [na escola da pesquisa] eu aprendi coisas que eu não gostava, que nem eu não gostava de ler livro, eu gosto de ler hoje, coisas assim. Que me ajudou também.

Confirmei, em conversa com a direção e a coordenação da escola, que não há investimento em planejamento ou projeto pedagógico visando, especificamente, à saída dos(as) jovens de oitava série. Os(as) jovens relatam alguns investimentos individuais de professoras que falaram sobre o assunto. Possuíam uma professora conselheira, que foi quem falou com eles sobre as opções para o Ensino Médio, alertou sobre prazo de inscrição etc. Juarez Dayrell (2005) aponta que é tarefa do mundo adulto auxiliar o jovem na organização e elaboração de um projeto de futuro, bem como das instituições sociais que nos organizam, como a escola, por exemplo, pois, para o autor, pensar o tempo porvir é uma questão de aprendizagem, de "aprender a escolher". Pesquisas vêm mostrando, no entanto, "que a instituição escolar, principalmente a escola pública, não vem cumprindo este papel. A escola pouco conhece o jovem que a frequenta, a sua visão de mundo, os seus desejos, o que faz fora da escola" (DAYRELL, 2005, p.37).

Como têm apontado outras pesquisas (DAYRELL, 2005; DAYRELL; CARRANO, 2014; FÉLIX, 2012; KLEIN, 2011; LEÃO, 2011; WELLER, 2014 - só para citar algumas) sobre o tema aqui estudado, a escola continua se mostrando para os(as) jovens como um importante lugar para a construção de futuro. Permanece a noção de que uma maior escolarização está necessariamente atrelada a um futuro de sucesso. Entretanto, também se mantém uma incoerente relação entre essa afirmação e outra, de que o que se aprende na escola pode não auxiliar, diretamente, nessas conquistas, mas quase todos(as) afirmaram que as professoras "ensinam bem". Na fala de Renata, vemos que há problemas mais amplos, como falta de professores, uma questão que ultrapassa a possibilidade de a escola suprir, já que é uma questão programática.

Renata: É um ensino bom assim, mas eu achei esse ano muito horrivel sabe. Como a gente está na $8^{a}$ série, a falta dos professores, principalmente de inglês, esse negócio de notas. Entendeu? Esse ano foi bem fraco, mas nos outros anos foi bem boa, a qualidade de ensino dos professores é boa, não é fraco, é uma matéria boa, assim eles facilitam bastante, eles fazem de tudo para não rodar e roda realmente quem quer.

A escolarização como imperativo parece se fixar, de modo mais intenso, na conquista de um diploma e no acesso a cursos ou projetos e políticas de governo. 
Os(as) jovens me permitiram compreender que sentem necessidade de um maior apoio e orientação da escola, principalmente no último ano, do que podem fazer "no ano que vem". Mostraram desconhecimento sobre o funcionamento do Ensino Médio e das opções de cursos e estágios que possuem. A busca por bolsas de estudos em escolas privadas foi resultado de empreendimentos individuais - a escola não informou nem auxiliou nesse processo. Entendo que um trabalho pedagógico intencional em torno da temática poderia orientar o fazer de professores e professoras dessas turmas, ao menos no último trimestre, a fim de que tenham tempo hábil para se organizar.

A saída da escola e a separação do grupo de colegas e de algumas amizades individuais também se mostraram, para alguns, questões a serem superadas e resolvidas.

Sandra: E como que tá sendo para ti essa situação de que daqui a pouco acaba e vocês vão ter que se separar?

Shape Door: Para mim não cain a ficha ainda.

Sandra: Ainda não?

Shape Door: Para mim ainda não cain a ficha, eu acho que a gente vai se ver muito ainda, até cair a ficha de que a gente não vai mais se ver... acho que gente vai combinar para sair, mas não cain a ficha.

$[\ldots]$

Sandra: Tá te sentindo preparado para sair, então?

Shape Door: Ainda não.

Sandra: Não?

Shape Door: Tô um pouco inseguro ainda, mas até o final do ano eu tô pronto.

Sandra: Porque que tu tá inseguro, o que tu pensa?

Shape Door: Porque eu acho que vai ser muito mais puxado e mais difícil e eu tô com medo de não me encaixar no ensino médio. Mas até o final do ano eu tô pronto.

Mariana: E dai eu vou para outra escola, uma turma o dobro do tamanho e ai tem que fazer tudo de novo [as amizades]? Bah, isso tudo é assustador para mim. É, ai a primeira vez que a minha mãe falou das escolas, que eu tinha que trocar, a primeira coisa que eu falei foi "eu tô indo para o ensino médio para estudar". Mas aí eu me imagino lá no recreio com um livro na mão e o fone de ouvido, sem falar com ninguém. A primeira coisa que me deu medo ao falar do ensino médio foi: tá, e o trabalho em grupo? Em dupla? Com quem que eu vou sentar?

Essa temática poderia fazer parte de um projeto final em diferentes disciplinas. Temas como esse ainda não se configuram, para boa parte das escolas, como um tema pedagógico, muito menos 
relevante. Aí, vê-se um descompasso entre os tempos dos(as) jovens e o tempo da escola. O que interessa mesmo neste momento de transição? Os(as) jovens pouco são interrogados no interior da escola sobre isso. A temática da juventude, tempo e escola, de forma ainda tímida, tem sido pauta de pesquisas acadêmicas, mas as escolas, de modo geral, ainda não perceberam aí um foco importante de aprendizagem.

Concordo com Weller (2014, p. 141), quando esta afirma que "a convivência no espaço escolar, os componentes curriculares com todos os seus limites, as atividades que extrapolam o contexto das aulas, assim como as relações estabelecidas com os profissionais da educação, são elementos constitutivos para projetos de vida".

O Centro Brasileiro de Análise e Planejamento (Cebrap), em 2012, investigou o tipo de relação que os jovens estabelecem com as escolas de Ensino Médio. O que chama a atenção entre essa pesquisa e a por mim realizada é a dificuldade que os(as) jovens têm de atribuir sentido às disciplinas e a alguns conteúdos estudados e como isso pode lhes ser útil em termos de futuro. Como vemos no excerto, Matemática e Português são ainda as disciplinas mais valorizadas; essa é uma hegemonia que tem se mantido ao longo do tempo, em função mesmo do modo como a carga horária das disciplinas é distribuída semanalmente e do peso que a elas é atribuído em processos seletivos como o vestibular, por exemplo.

Shape Door: Geografia não é importante, mas vai precisar.

Sandra: Vai precisar para quê?

Shape Door: Sei lá, se eu tiver que viajar, eu acho. Não sei. Só educação física que eu também não acho que ajuda.

Sandra: Hã, deixa eu ver, e a matemática?

Shape Door: Ah, a matemática sim, porque para o cara administrar ele tem que saber lidar com números e tudo mais. Português também, para aprender a falar e coisa. Esses dois são praticamente a base para poder ser alguém.

A pesquisa do Cebrap revelou, também, que um em cada cinco alunos só frequenta a escola para obter o diploma.

"O resultado confirma o que já tínhamos verificado: o jovem de hoje não vê o menor sentido no que aprende na aula. Ele se sente conectado com a vida, mas desconectado com a escola", observa Priscila Cruz, diretora executiva do Todos pela Educação. Para resolver o problema da fragmentação curricular - no Ensino Médio, o aluno chega a estudar 13 disciplinas -, ela propõe uma flexibilização. "A grade curricular pode permitir a liberdade de escolha. Na adolescência, muitos sabem do que gostam e do que não gostam. Se a escola for um lugar onde o estudante consegue construir um projeto de vida, vai se sentir motivado a frequentá-la”. (FUNDAÇÃO VICTOR CIVITA, 2012, s/p) 
Essa questão também foi apontada pelos(as) jovens entrevistados(as), embora de modo mais sutil. $\mathrm{Na}$ minha pesquisa, o interesse pelo diploma foca a certificação de uma profissão.

\section{PONDERAÇ̃̃ES FINAIS}

Não há informações propriamente novas com a pesquisa, mas, sim, um reforçamento do que outras pesquisas já vêm encontrando: a escola ainda é para os(as) jovens um lugar sem precedentes para a construção de futuro. É preciso passar pela escola para ser alguém na vida. O imperativo da escolarização parece muito ancorado na conquista de um diploma e no acesso a cursos ou projetos e políticas de governo. A escola ainda não percebeu o nicho que se oferta nessa posição que ocupa e deixa de consagrar esse lugar como possibilidade de intervenção (apoio, contribuição, suporte ou subsídio) nos processos de transição dos alunos. Não aproveita esse período de vida dos(as) jovens estudantes como um evento para intervenções pedagógicas, potentes e funcionais, agenciando-se como lugar da experiência.

Somos constantemente tensionados pelas diferenças temporais que marcam professores(as) e alunos(as). Como mencionado anteriormente, eles e elas habitam outros tempos, vestem-se de outras corporeidades que, muitas vezes, não conseguimos adentrar e se colocam em confronto com aquilo que aprendemos e construímos. São conflitos ou somente diferenças geracionais que podem afastar ou cercear as relações, as convivências, as aprendizagens. Olhamos para eles e elas como puros outros, como "os" sujeitos da diferença ou da falta. Não percebemos que essa é uma via de mão dupla em que o outro também pode ser eu mesmo e que a diferença é do ser humano, e não de uma parcela dele. Ocupamos um tempo que precisa ser habitado por alguém, o tempo passado, dos antigos, dos mais velhos, fazemos parte de outra geração. Talvez a pergunta possível seja: há a possibilidade de transformar essa aparente incompatibilidade temporal em troca de experiências?

Por fim, os(as) entrevistados(as) apontaram a importância da escola como espaço de socialização, de amizade, de pertencimento e que a separação do grupo estava sendo vivida como um momento de luto para muitos(as). A escola, entretanto, pouco reconhece as relações e interações entre os(as) jovens como práticas sociais que envolvem processos educativos legítimos e que poderiam, assim, compreender o conjunto de temáticas a serem discutidas neste ano de transição escolar (muitas vezes), de modalidade de ensino (para muitos) e mesmo de vida (para outros tantos que adentram o mercado de trabalho). 


\section{REFERÊNCIAS}

ANDRADE, Sandra dos Santos. Juventudes e processos de escolarização: uma abordagem cultural. 2008. 258 f. Tese (Doutorado em Educação) - Programa de PósGraduação em Educação, Faculdade de Educação, Universidade Federal do Rio Grande do Sul, Porto Alegre. 2008.

ANDRADE, Sandra dos Santos. A entrevista narrativa ressignificada nas pesquisas educacionais pós-estruturalistas. In: MEYER, Dagmar E.; PARAÍSO, Marlucy Alves. Metodologias de pesquisa pós-críticas em educação. Belo Horizonte: Mazza Edições, 2014. p. 173-194.

COSTA, Luis Artur; FONSECA, Tânia Mara Galli. Do contemporâneo: o tempo na história do presente. Arquivos Brasileiros de Psicologia, v. 59, n. 2, p. 110-118, 2007. Disponível em: <http://www.redalyc.org/pdf/2290/229017529002.pdf>. Acesso em: 28 nov. 2014.

COSTA, Marisa Vorraber. A escola rouba a cena. In: COSTA, Marisa Vorraber (Org.). A escola tem futuro? Rio de Janeiro: DP\&A, 2003. p. 11-22.

DAMICO, José Geraldo Soares. Juventudes governadas: dispositivos de segurança e participação no Guajuviras (Canoas-RS) e em Grigny Centre (França). 2011. 290 f. Tese (Doutorado em Educação) - Programa de Pós-Graduação em Educação, Faculdade de Educação, Universidade Federal do Rio Grande do Sul, Porto Alegre. 2011.

DAYRELL, Juarez. A escola precisa reconhecer o jovem por trás do aluno e adaptar a ele seus processos educativos. Onda Jovem, v.1, n.1, p. 34-37, mar. 2005.

DAYRELL, Juarez; CARRANO, Paulo. Juventude e ensino médio: quem é este aluno que chega à escola? In: DAYRELL, Juarez; CARRANO, Paulo; MAIA, Carla Linhares. Juventude e ensino médio: sujeitos e currículo em diálogo. Belo Horizonte: Editora UFMG, 2014. p. 101-133.

ESCRITORES da Liberdade. Direção: Richard Lagravenese. Produção: Richard Lagravenese. Roteiro: Richard Lagravenese. Intérpretes: Hilary Swank, Patrick Dempsey, Scott Glenn, Imelda Staunton, April L. Hernandez e outros. Alemanha/EUA: Stúdio Paramount Pictures, 2007. 1 filme (123 min), son., color., $35 \mathrm{~mm}$.

ELIAS, Norbert. Sobre o tempo. Rio de Janeiro: Jorge Zahar Ed., 1998.

FÉLIX, Jeane. “Quer teclar?”: aprendizagens sobre juventudes e soropositividades através de bate-papos virtuais. 2012. 223 f. Tese (Doutorado em Educação) - Programa de PósGraduação em Educação, Faculdade de Educação, Universidade Federal do Rio Grande do Sul, Porto Alegre. 2012.

FISCHER, Rosa Maria Bueno. Televisão e educação: fruir e pensar a TV. Belo Horizonte: Autêntica, 2001.

FOUCAULT, Michel. A arqueologia do saber. Rio de Janeiro: Forense Universitária, 2000. FRANK, Anne. O diário de Anne Frank. São Paulo: Best Bolso, 2011.

FUNDAÇÃO VICTOR CIVITA. O que pensam os jovens de baixa renda sobre a escola. 2012. Disponível em: <http://fvc.org.br/estudos-e-pesquisas/2012/pensamjovens-baixa-renda-escola-743754.shtml>. Acesso em: 9 jan. 2014.

GUIMARÃES, Antônio Sérgio. Classes, raças e democracia. São Paulo: Editora 34, 2002.

KLEIN, Ana Maria. Projetos de vida e escola: a percepção de estudantes de Ensino Médio sobre as contribuições das experiências escolares aos seus projetos de vida. 2011. $290 \mathrm{f}$. Tese (Doutorado em Educação) - Programa de Pós-Graduação em Educação, Faculdade de Educação, Universidade de São Paulo, São Paulo. 2011. 
KLEIN, Carin; DAMICO, José. O uso da etnografia pós-moderna para a investigação de políticas públicas de inclusão social. In: MEYER, Dagmar E.; PARAÍSO, Marlucy Alves. Metodologias de pesquisa pós-críticas em educação. Belo Horizonte: Mazza Edições, 2014. p. 63-86.

LEÃO, Geraldo. Entre sonhos e projetos de jovens, a escola... In: DAYRELL, Juarez; MOREIRA, Maria Ignez Costa;STENGEL, Márcia(Org.). Juventudes contemporâneas: um mosaico de possibilidades. Belo Horizonte: Ed. PUC Minas, 2011. p. 99-116.

LECCARDI, Carmen. Por um novo significado de futuro: mudança social, jovens e tempo. Revista de Sociologia da USP, São Paulo, v. 17, n. 2, p. 35-57, 2005.

MELUCCI, Alberto. Juventude, tempo e movimentos sociais. Revista Brasileira de Educação, São Paulo, n. 5-6, p. 5-14, maio/dez. 1997.

MEYER, Dagmar E. Estermann. Identidades traduzidas: cultura e docência teutobrasileiro-evangélico no Rio Grande do Sul. Santa Cruz do Sul: EDUNISC; São Leopoldo: Sinodal, 2000.

MEYER, Dagmar; FÉLIX, Jeane. "Entre o ser e o queres ser...” jovens soropositivos/as projetos de vida e educação. Educação em Revista, Belo Horizonte, v. 30, n.2, p. 181-206, abr./jun. 2014.

PINTO, Céli Regina. Com a palavra o senhor presidente José Sarney: ou como entender os meandros da linguagem do poder. São Paulo: Hucitec, 1989.

WELLER, Vivian. Jovens no ensino médio: projetos de vida e perspectivas de futuro. In: DAYRELL, Juarez; CARRANO, Paulo; MAIA, Carla Linhares. Juventude e ensino médio: sujeitos e currículo em diálogo. Belo Horizonte: Editora UFMG, 2014. p. 135-154.

\section{NOTAS}

${ }^{1}$ Este texto é um recorte de minha pesquisa de pós-doutorado realizada no Programa de Pós-graduação em Educação da Universidade Federal do Rio Grande, sob a supervisão da Prof ${ }^{\mathrm{a}}$. Dra. Dagmar E. Meyer, com financiamento da Capes no ano de 2014.

${ }^{2}$ Após assistir ao filme Escritores da liberdade(2007), que serviria de inspiração para as escritas individuais sobre futuro, conversamos sobre o livro de Anne Frank (2011), e algumas alunas sugeriram que escrevessem também um diário. Comprei cadernos para todos, personalizamos a capa e quem quis utilizou o caderno para suas reflexões. Ao final do semestre, recolhi o caderno de quem me autorizou e fiz cópia.

${ }^{3}$ Os nomes dos(as) entrevistados(as) são fictícios, escolhidos pelos(as) próprios(as) jovens. Todos os excertos das entrevistas serão apresentados em itálico para diferenciar das citações.

${ }^{4}$ Centro de treinamento que funciona como curso preparatório para concursos das Carreiras Militares das Forças Armadas para jovens dos 10 aos 20 anos. Por meio de processo seletivo, o centro selecionou alguns jovens da escola para fazer o curso.

${ }^{5}$ Enquanto escrevia este texto, no fim do ano seguinte ao das entrevistas, Dudu coloca no Facebook o seguinte comentário "Eeeeeh crl toow passado... Pra quem duvidou de mim, CHORA $B O Y$ !" A-P-R-O-V-A-D-O :P=D. Esse comentário reforça o sentimento que perpassa a maioria dos(as) jovens, e que é tomado do senso comum, de que ser mais bem-sucedido ou capaz implica se dar bem na escola. Ou seja, Dudu comemora a aprovação no ano seguinte, deixando entrever os efeitos que a repetência e a posterior aprovação no último ano do Ensino Fundamental provocaram na constituição de si.

${ }^{6}$ Cf. ANDRADE, 2008. 
Submetido: 05/01/2016 Aprovado: 16/05/2016

Contato:

Rua Sinimbu, 129/502

Bairro Petrópolis

Porto Alegre |RS | Brasil

CEP 90.470-470 